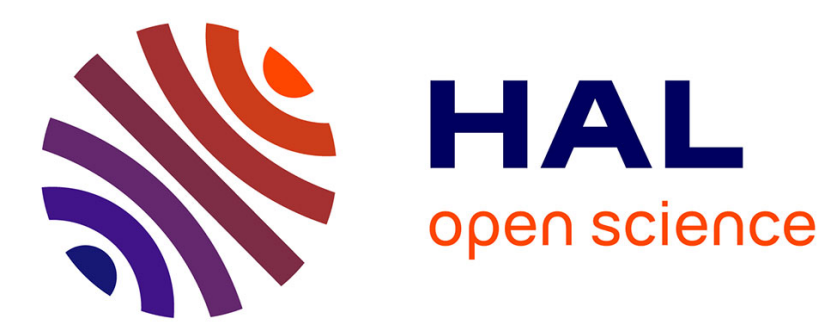

\title{
Salvaging the records of salvage ethnography: The story of the Digital Himalaya Project
}

\author{
Mark Turin
}

\section{To cite this version:}

Mark Turin. Salvaging the records of salvage ethnography: The story of the Digital Himalaya Project. Book 2.0, 2012, 1 (1), pp.39-46. 10.1386/btwo.1.1.39_1 . halshs-03083432

\section{HAL Id: halshs-03083432 \\ https://shs.hal.science/halshs-03083432}

Submitted on 27 Jan 2021

HAL is a multi-disciplinary open access archive for the deposit and dissemination of scientific research documents, whether they are published or not. The documents may come from teaching and research institutions in France or abroad, or from public or private research centers.
L'archive ouverte pluridisciplinaire HAL, est destinée au dépôt et à la diffusion de documents scientifiques de niveau recherche, publiés ou non, émanant des établissements d'enseignement et de recherche français ou étrangers, des laboratoires publics ou privés. 
Book 2.0

Volume 1 Number 1

(C) 2011 Intellect Ltd Article. English language. doi: 10.1386/btwo.1.1.39_1

\title{
Salvaging the records of salvage ethnography: The story of the Digital Himalaya Project
}

\begin{abstract}
The Digital Himalaya Project is a collection, storage and dissemination portal for scholarly content and research findings about the Himalayan region. The project website connects a worldwide user community to a vast corpus of digital resources from or about India, Nepal, Bhutan and the Tibetan plateau for free and easy download - without payment, subscription or password.

While Digital Himalaya began as a strategy for collecting and protecting the products of colonial-era ethnographic collections on the Himalayas - for posterity and for access by source communities - the project has now become a collaborative digital publishing environment, bringing a new collection online every month, with close to half a million web visitors since its establishment in 2000.

Almost all of our digitization and scanning is now conducted in Nepal, dramatically reducing operating costs and increasing productivity. Our funding no longer comes from research councils in the United Kingdom and the United States, but through web referrals and from individual or institutional donations around the world. The project is now supported by people and organizations that recognize the work and want to contribute to it.
\end{abstract}

\section{KEYWORDS}

archive

Bhutan

collaboration

collection

curation

digital

ethnography

heritage

Himalaya

Nepal

web publishing 
In short, what began as an academic research project a decade ago is now a vast online portal for hosting and disseminating knowledge about the Himalayas to a demanding, fast-growing and truly global user base.

\section{THE PROJECT'S ORIGINS}

In December 2000, together with Professor Alan Macfarlane, Sarah Harrison and Dr Sara Shneiderman, I established the Digital Himalaya Project at the University of Cambridge to develop digital collection, storage and distribution strategies for multimedia anthropological information from the Himalayan region. The plan was simple enough and we felt that the timing was right: many archival ethnographic materials, such as $16 \mathrm{~mm}$ films, still photographs, videos, sound recordings, field notes, maps and rare journals were fast degenerating in their current formats. As we were anthropologists who worked in Nepal - with the Gurung (Tamu) and Thami (Thangmi) communities - it was logical that we focused our attention on the Himalayas.

During our research we noted a peculiar paradox. Even though anthropologists were becoming ever more concerned about cultural endangerment and the damaging side effects of globalization, and funds were available for scholars to document indigenous cultures that were fast disappearing, very few social scientists were working to ensure that anthropological collections from previous generations were maintained, refreshed and made accessible, both to the research community and to the descendants of the people from whom the materials were collected. To this end, we applied to the Royal Anthropological Institute in the United Kingdom for a grant to set up the Digital Himalaya Project as a strategy for archiving, digitizing and disseminating online legacy ethnographic materials concerning the Himalayan region.

A little seed-corn funding, a small research team and a growing sense that what was still being referred to as 'the World Wide Web' was robust enough to deliver compressed video on demand all came together to energize our fledgling project. Alongside the preservation aspect mentioned above, we had two other primary aims: to make our digital resources available over broadband Internet connections for researchers and students and to return copies to source communities in the countries of origin - such as Nepal, Bhutan, the Tibetan Autonomous Region and the Himalayan states of India. When we started the project, we had naïvely imagined that the West would have the Internet and 'the Rest' would have DVDs and CD-ROMs. How wrong we were!

\section{TECHNOLOGY AS A MASTER CLASS IN BUDDHISM}

Archivists specializing in the curation of moving images use the phrase 'nitrate won't wait' to describe the urgency of migrating silver nitrate film to more durable digital formats. Not only were anthropological collections dating from the early twentieth century fast degrading, but they were also becoming orphaned, as the technology needed to view them was now obsolete and ever harder to find. The pace of technological adaptation and change provides a powerful if brutal lesson in impermanence and non-attachment: it is still possible to read a book that is 500 years old (as many scholars of classical languages and cultures regularly do), but close to impossible to find a computer anywhere within the University of Cambridge that can read an 'old' 8-inch or 51/4-inch floppy disc dating back to the 1980s. The rate of innovation and obsolescence moves ever faster and few fieldworkers pause to reflect on issues 
such as the longevity and persistence of their recordings before they travel to remote locations around the world to document endangered cultures.

There was a further irony in what we planned to do. While 'audio-visual' was a big technology buzzword in the 1990s, ethnographic fieldwork had been 'multimedia' or 'multimodal' for about 100 years, with early anthropologists using still cameras, wax or plastic cylinder record phonographs and copious notebooks to document their personal reflections. When these scholars returned home, though, they were expected to write books in which precious little of the material that they had recorded could be accommodated. And when anthropologists retired, and later passed away, their collections of recordings and photographs were left in shoeboxes in their attic, only to be passed on to university libraries and archives that did not really want them or know how to catalogue them. So while fieldwork was inherently immersive, making use of all manner of technology, an anthropologist's holistic collection would be split apart when it returned home, according to the format of the recording medium: text, to the library; sound, to the audio archives; photographs, to the photo collections; and cine film, often nowhere. The fast-developing Web was the natural site for these diverse materials to be reintegrated and served up in a rich, searchable and retrievable multimedia format.

\section{FILM COLLECTIONS}

In the first phase of the project, five ethnographic collections - representing a broad range of regions, ethnic groups, time periods and themes - were selected for digitization, along with a set of maps of Nepal and some important journals on Himalayan studies. One of the most valuable collections was that of the $16 \mathrm{~mm}$ films taken by Christoph von Fürer-Haimendorf, a professor of anthropology at the School of Oriental and African Studies (SOAS) in London, which spanned from the 1930s to the 1980s. While FürerHaimendorf's specific interests included the Naga communities of India and the Sherpa of Nepal, he travelled far and wide across the region, taking over 100 hours of film throughout his career. Extraordinary in both its breadth and its depth, his collection is one of the finest extant ethnographic film collections that document Himalayan cultures.

We started digitizing Fürer-Haimendorf's films in a cheap and cheerful way ourselves (see Figure 1), by projecting the footage and then filming the output through a box of mirrors and hosting video clips on our website. These snippets caught the attention of the British Universities Film and Video Council (BUFVC) who then paid for the professional digitization of the footage using telecine projection. Herein lay another lesson: digitization is a continuous and ongoing process, not simply a one-off; and we began to think of digitizing a subset first before committing to undertake the digitization of an entire collection.

Another important early collection for the project was that of Frederick Williamson, a British political officer stationed in Sikkim in the 1930s. He was also an ardent photographer and amateur film-maker. Between 1930 and 1935, he and his wife, Margaret, took approximately 1700 photographs throughout the region. As well as documenting the Williamsons' travels, their photos provide an unusually well-preserved and well-catalogued insight into social life in Sikkim, Bhutan and Tibet during the 1930s. Of particular interest to us were the 23 reels of $16 \mathrm{~mm}$ cine film that Williamson shot while on official trips. We digitized these films (see Figure 2), then returned to Sikkim, Bhutan and Tibet with sets of DVDs to make them available to institutes, 


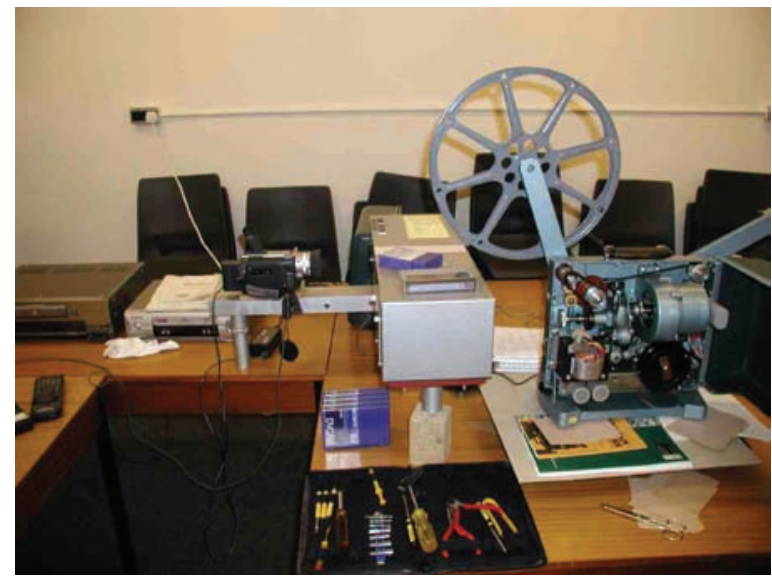

Figure 1. Heath Robinson-style digitisation: using a SONY Color Film Chain Adaptor, 16mm projector and a digital camera. Cambridge 2001.

universities and colleges in the region, as well as to the descendants of some of the people we could identify from the footage.

Through the Fürer-Haimendorf and Williamson film collections, interesting and unexpected collaborations began to take place. The custodians of such collections back in the United Kingdom often had only a limited knowledge about the context of the footage that they held, based on a few quickly scribbled notes on a film canister or from an ancient accession form. Back in the Himalayas, however, descendants of the individuals who featured in these films could often provide a great deal of additional information about the footage and their insights added enormous value to the collections. Returning to source communities with DVDs and hard discs, then, was not simply a mechanical process of cultural repatriation in digital form, but rather an exciting opportunity for partnerships by which collections were enriched and better understood, and copies of the footage distributed to the communities who had a stake in its maintenance and content (see Figures 3 and 4).

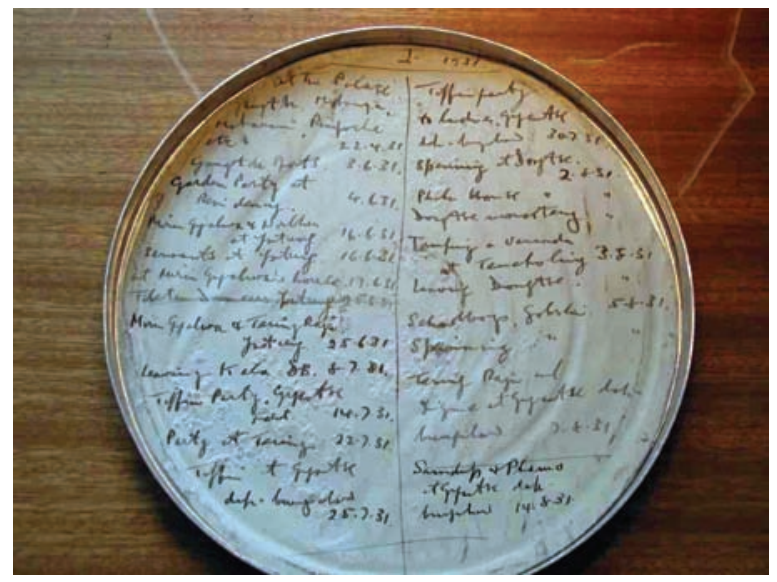

Figure 2. Frederick Williamson's hand-written shooting log inside the film canister from his 1931 trip to Tibet. 


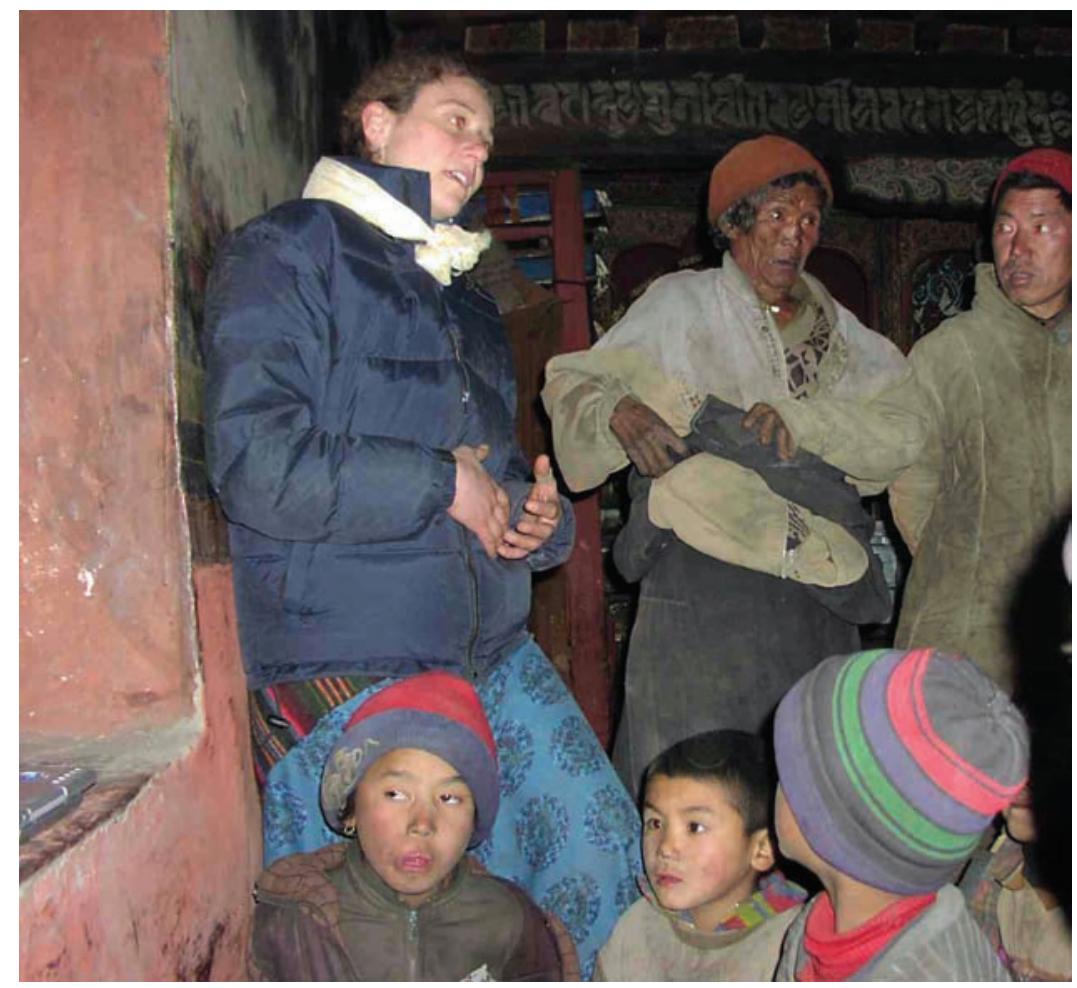

Figure 3. Sara Shneiderman introducing Christoph von Fürer-Haimendorf's 1962 footage of Lubra, Nepal, to contemporary residents of the village. Photo by Sienna Craig, December 2002.

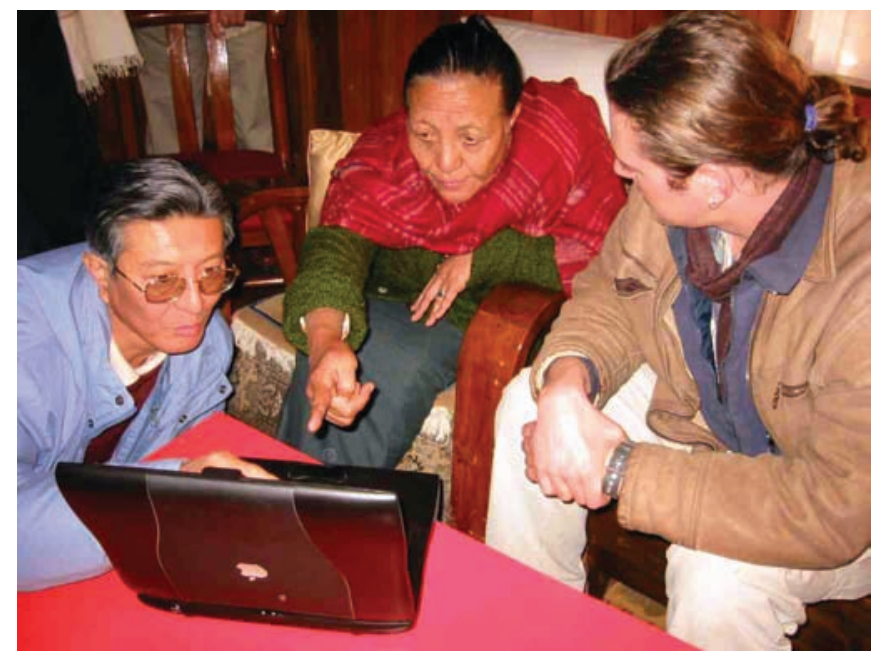

Figure 4. From left: the late Khendzong Yapla (Secretary to the Government of Sikkim and local cultural historian), his late mother and Mark Turin viewing Williamson's 1930s footage of Sikkim, in Gangtok, Sikkim, India. Photo by Sara Shneiderman, January 2003. 


\section{JOURNALS, MAPS AND THE NEPALI CENSUS}

It became apparent that we were in a position to expand Digital Himalaya to benefit an ever-wider base of individuals around the world who were connected to the Internet. As scholars, we were frequent users of digital versions of academic journals available through services such as JSTOR, but we were surprised to discover that no publications that originated in Himalayan countries could be found in such online archives, severely constraining access and visibility. With the agreement of editorial boards and publishers, we started sourcing and scanning back issues of a large number of journals, magazines and publications on Himalayan studies from Nepal, Bhutan, India and Tibet, as well as publications relating to the region that originated in Europe and the United States.

After years of scanning, we now host back issues of many important publications online for free download, including but not limited to: Ancient Nepal, Adarsh; Bulletin of Tibetology; Contributions to Nepalese Studies; European Bulletin of Himalayan Research; Gochali, Himal; Himal Southasian; Himalayan Journal of Sciences; Journal of Bhutan Studies; Journal of Newar Studies; Journal of the Tibet Society; Kailash - Journal of Himalayan Studies; Martin Chautari Policy Briefs; Mulyankan; Nation Weekly; Nepalese Linguistics; Nepali Times; Newsfront; Occasional Papers in Sociology and Anthropology; Peace and Democracy in South Asia; Purnima; Read; Regmi Research Series; Revue d'Etudes Tibétaines; Sharada; Shikshak.

The idea is simple: we want to stimulate sales and subscriptions by digitizing and hosting back issues (at no cost to the publisher), many of which are now out of print, and thus provide a web presence for print collections that might otherwise not have made it online. We have found our PDF archive of journals and magazines to be amazingly popular, especially within Himalayan states themselves, where access to good libraries and full collections of printed matter is often poor. Having started with a few journals (Kailash - Journal of Himalayan Studies was the first), we soon established a momentum and visibility such that others wanted to join the initiative. Now that we run optical character recognition software over each article, it is possible to search the content of a journal (as long as it was originally printed in a Roman script), and all articles are indexed by Google.

Together with Dr Ken Bauer, we produced a series of maps of each of Nepal's 75 districts based on GIS layers showing rivers, roads, settlements and elevation, all of which are widely used and freely available through our website. We also built an online tool to query data from the 2001 National Census of Nepal, allowing users to download data on economic activity, literacy, marital status, religion, population and school status in four different file formats: .xls, .pdf, .txt and .html. These resources are proving to be very popular the world over, and particularly among students, NGOs and journalists in the region, which is very satisfying.

\section{OUR TEAM}

Aside from Alan Macfarlane and myself, there were two other founding members of the project: Sarah Harrison and Sara Shneiderman, both scholars of Nepal, and coincidentally also our wives. Sarah and Sara did an enormous amount of the early work - including designing and hosting our first web presence and preparing collections for online dissemination. As the project developed and changed direction over the years, many other people have become involved. I would like to mention in particular Daniel Ho of New York, a very talented artist and web designer (a rare combination in one person); Hikmat Khadka, a skilled translator and user of Nepali Unicode who 
joined us for six months in Cambridge last year; and Komin Thami, our office manager and principal scanner based in Kathmandu. Digital Himalaya has matured from being a UK-based university initiative to a multi-site online portal with team members in three continents making use of Skype, Gmail and file transfer services like YouSendIt to work together and ensure that new collections can be hosted online as efficiently as possible.

\section{PROJECT MOVEMENTS}

From 2002 to 2005, the project moved to the Department of Anthropology at Cornell University and began its partnership with the University of Virginia. As of 2011, Digital Himalaya is colocated at Cambridge and Yale universities. These various moves have added a great deal to the project and our collections. I will never forget my joy at seeing the first automatic document feeder scanner, which ingested A4 print outs and spat out a perfect PDF! We made good use of this machine, along with many others, and we now have well over 200,000 pages of text online.

\section{OUR USERS}

For a long time, we had no idea of how many users we had and where they were based, but through Google Analytics, we now have a much better sense. Most of our users come from four countries: India; Nepal; the United States; and the United Kingdom, but there are sizeable numbers of repeat visitors from Europe and South America also. On an average day, we receive between 150-300 visits to our site, and many people spend some time downloading movies, audio files or documents from our servers that they can view on their own computers or handheld devices once they are no longer connected to the Web.

\section{THE UNEXPECTED}

While the project began as a strategy for salvaging, archiving and disseminating the products of (primarily colonial) ethnographic collections on the Himalayas both for posterity and for heritage communities - Digital Himalaya has become a collaborative digital publishing environment which brings a new collection online every month. The website has grown from a static homepage with occasional updates to a dynamic content delivery platform for over 40GB of archived data. Similarly, our website has moved from being almost exclusively used by members of western universities to providing a range of services to a global public, with a particularly strong user base in Asia. Digitization has been 'off-shored' to Nepal, dramatically reducing operational costs and increasing productivity and connectivity with local communities. And perhaps most importantly, our funding no longer comes from national grant-giving bodies in Europe or the United States, but from users, web referrals and individual donations from around the world. It has been an exciting, unexpected and very rewarding process, and we continue to receive grateful e-mails as well as frustrated e-mails from users when links do not work (please do tell us), alongside recommendations of areas into which we might expand.

\section{REFERENCES}

Digital Himalaya, http://www.digitalhimalaya.com/. Accessed 13 October 2011. Cambridge University Museum of Archaeology and Anthropology, http:// maa.cam.ac.uk/home/index.php/. Accessed 13 October 2011. 
Royal Anthropological Institute, http://www.therai.org.uk/. Accessed 13 October 2011.

Vanishing Worlds Foundation, http://vanishingworlds.wordpress.com/. Accessed 13 October 2011.

\section{SUGGESTED CITATION}

Turin, M. (2011), 'Salvaging the records of salvage ethnography: The story of the Digital Himalaya Project.', Book 2.0 1: 1, pp. 39-46, doi: 10.1386/btwo.1.1.39_1

\section{CONTRIBUTOR DETAILS}

Mark Turin was trained in social anthropology at the University of Cambridge after which he spent a year cataloguing Christoph von Fürer-Haimendorf's ethnographic films. Then he joined the Himalayan Languages Project at Leiden University, the Netherlands, to write a grammar of Thangmi, a hitherto undescribed Tibeto-Burman language spoken in eastern Nepal. His doctoral dissertation offers an analysis of the grammar of the Thangmi language supported by glossed texts and a comprehensive lexicon of the two main dialects.

Mark currently directs the Digital Himalaya Project and the World Oral Literature Project. He is an associate research scientist at the South Asian Studies Council, Yale University; a research associate at the Museum of Archaeology and Anthropology in Cambridge; an honorary research fellow at Anglia Ruskin University and a fellow of Hughes Hall, University of Cambridge.

E-mail: digitalhimalaya@gmail.com 